\title{
Fine structure of cutaneous nerves in ganglioside storage disease
}

\author{
C. L. D O L M A N, P. M. M a c L E O D, A N D E. CH A N G
}

From the Departments of Pathology and Medical Genetics, Vancouver General Hospital and the University of British Columbia, Vancouver, BC, Canada

SUMMARY Skin punch biopsies of six children suffering from infantile or late onset TaySachs disease, juvenile Sandhoff disease, or GM gangliosidosis type I, contained axons which, when viewed with the electron microscope, were distended by large amorphous black deposits. These are nonspecific residual bodies. Their large numbers indicate severe disturbance of the nerve cell and may be part of the dying back process. The three cases with Tay-Sachs disease had also axonal zebra or complex membranous bodies which appeared to be specific. Cytoplasmic vacuolation of other cells was a feature in the patient with $\mathrm{GM}_{1}$ gangliosidosis. Biopsies of three parents were negative.

The usefulness of skin biopsies in the diagnosis of the neurovisceral ceroid lipofuscinoses was pointed out by Carpenter et al., in 1972. This method was later investigated in other storage diseases (Dolman et al., 1975, O'Brien et al., 1975). Andermann et al. (1975) reported negative skin and nerve biopsies in two Lebanese brothers with late onset $\mathrm{GM}_{2}$ gangliosidosis. O'Brien et al. (1975) found sparse vacuoles in the epithelium of sweat glands and in endothelial cells in a biopsy specimen of skin of a child with $\mathrm{GM}_{1}$ gangliosidosis, type I, but no changes in the axons. In a brain biopsy, on the other hand, Buxton et al. (1972) described membranous cytoplasmic bodies and dense granular material in myelinated axons in a 9 year old boy suffering from $\mathbf{G M}_{2}$ gangliosidosis of late onset, and Patel et al. (1974) saw axons filled with amorphous granular debris and dense lamellar bodies in the cerebral cortex, and membranous cytoplasmic bodies in one myelinated axon in a spinal ganglion of a 6 year old boy who had died of $\mathbf{G M}_{1}$ gangliosidosis, type 2 . We shall describe the abnormal axonal deposits encountered in skin biopsy samples of six children with various gangliosidoses.

Presented in part at the meeting of the American Association of Neuropathologists, San Francisco, June 1976.

Address for correspondence and reprint requests: Dr C. L. Dolman, Pathology Department, Vancouver General Hospital, 855 West 12th Avenue, Vancouver, BC, V5Z 1MQ, Canada.

Accepted 17 December 1976

\section{Methods}

The skin of the deltoid region was infiltrated with local anaesthetic and biopsy samples taken with dermatological skin punches. One was used for fibroblast culture, the other was fixed in cold $2.5 \%$ buffered glutaraldehyde, cut into small pieces, washed in buffer, and embedded in plastic. Sections were cut $1 \mu \mathrm{m}$ thick, stained with toluidine blue, and blocks containing myelinated and unmyelinated nerves prepared for electron microscopy.

\section{Observations}

CASE 1 INFANTILE GM.2 GANGLIOSIDOSIS (CLASSICAL TAY-SACHS DISEASE)

A boy developed psychomotor retardation, convulsions, and cherry-red spots at the maculae at 10 months of age. Hexosaminidase A activity was nearly absent in leucocytes and cultured fibroblasts. In a skin biopsy specimen, taken at 2 years, several axons contained abnormal inclusions. Some of these were 'zebra bodies', composed of parallel laminae of triple membranes (Fig. 1). More common were membrane-bound, electrondense deposits, exhibiting little internal structure. These were especially prominent in nerve twigs in smooth muscle. Zebra bodies sometimes lay adjacent to dense bodies and numerous mitochondria were packed between them. A skin biopsy of the mother was negative. 


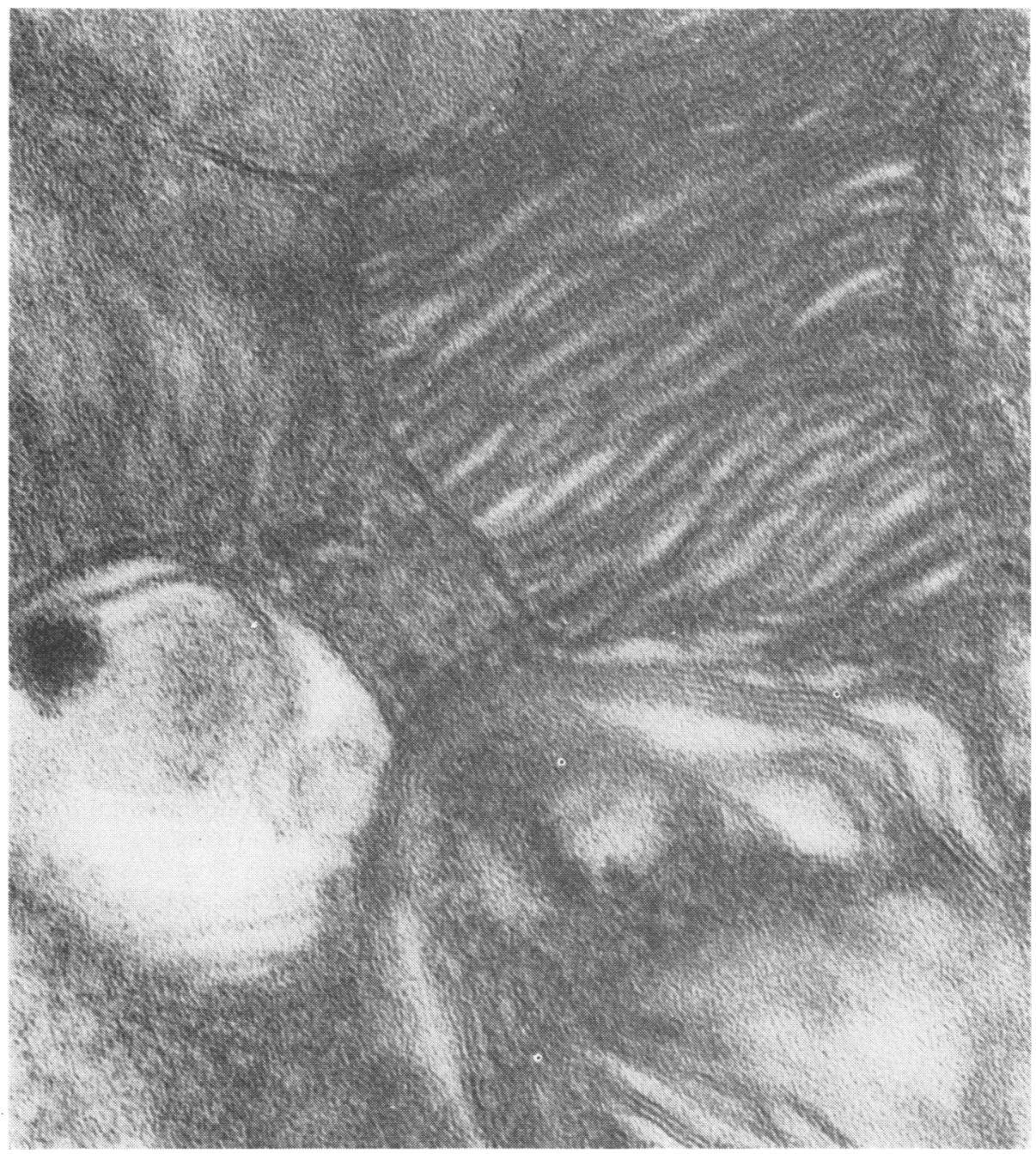

Fig. 1 Case 1. Infantile Tay-Sachs disease. Zebra bodies composed of triple layered membranes in cutaneous axon. $\times 219000$. 
CASE 2 LATE INFANTILE GM $_{2}$ GANGLIOSIDOSIS

A skin biopsy was obtained from a 4 year old boy with clinical and biochemical findings identical to the first boy, only with onset at 2 years. Abnormal inclusions were found in myelinated and unmyelinated axons. Complex membrane-bound zebra bodies, with individual bundles of parallel lamellae arranged at angles to each other, lay interspersed with electron-dense round bodies or membranous cytoplasmic bodies with a dense centre (Figs. 2, 3, 4). Mitochondria were closely associated. Nerve fibres within smooth muscle were again particularly affected and were striking by their big black inclusions.

This child has recently died and portions of his formalin-fixed brain were received for study. Microscopically, the nerve cells throughout the brain were distended by material which stained blue in paraffin sections by Luxol fast blue and deep pink in frozen sections by the periodic acidSchiff reagent. Under the electron microscope, the

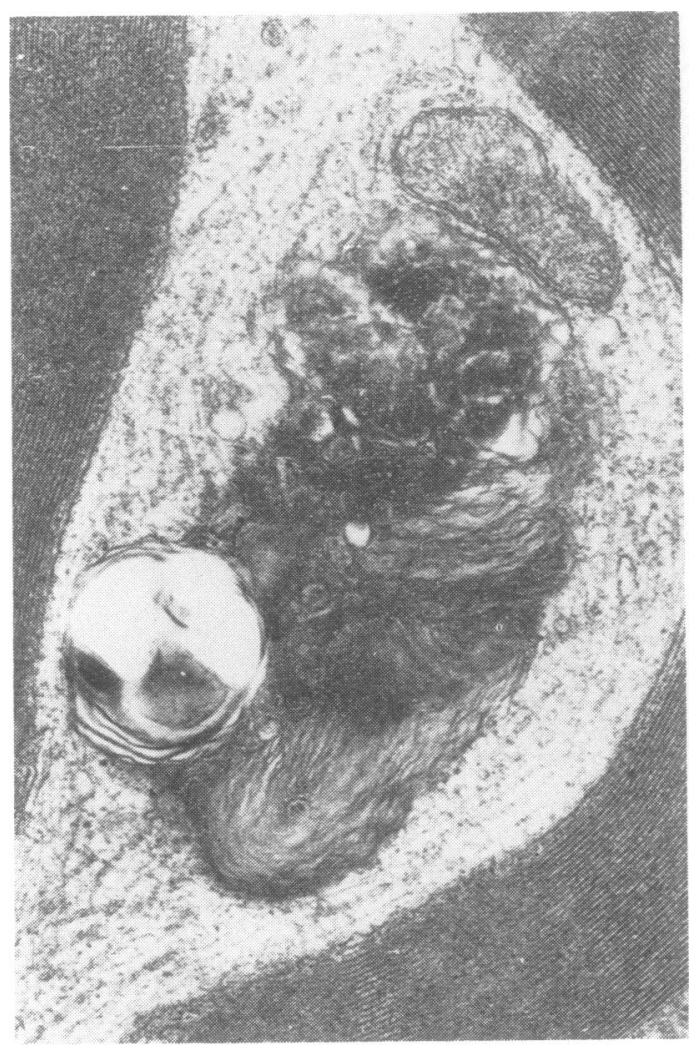

Fig. 2 Case 2. Late onset Tay-Sachs disease. Mixed membranous lipid and amorphous dense inclusion in myelinated cutaneous axon. $\times 40600$. stored material consisted of typical membranous cytoplasmic bodies, zebra bodies, or mixtures of the two. An occasional myelinated axon contained similar material intermingled with amorphous debris.

\section{CASE 3 LATE INFANTILE GM $_{2}$ GANGLIOSIDOSIS}

A 2 year old girl developed symptoms and signs identical to the first two cases, and her fibroblasts exhibited negligible hexosaminidase A activity. In a skin biopsy taken at the age of 6 years, several axons contained membrane-bound complex zebra bodies and electron-dense, usually homogeneous, only occasionally somewhat laminated structures intermingled with a multitude of mitochondria.

\section{CASE 4 JUVENILE SANDHOFF DISEASE}

A skin biopsy sample was obtained from an 11 year old boy whose history dated back to age 4 years, when he was found to be retarded and from then on developed increasing cerebellar deficit. Hexosaminidase A and B levels were severely reduced. Several cutaneous axons contained numerous amorphous osmiophilic deposits, particularly in nerve twigs in smooth muscle (Fig. 5). Occasionally, typical membrane-bound zebra bodies were present in the cytoplasm of Schwann cells (Fig. 6).

\section{CASE 5 JUVENILE SANDHOFF DISEASE}

A boy developed cerebellar symptoms at 4 years and mental retardation at 6 years. Fibroblast culture showed nearly complete total hexosaminidase deficiency. In a skin biopsy at age 10 years, the axons of many unmyelinated nerve fascicles were distended by multiple membrane-bound osmiophilic inclusions. Most of these were unstructured dense bodies (Fig. 7) and only occasionally had some concentric lamellae which, however, did not resemble true membranous cytoplasmic bodies. No abnormalities were seen in Schwann cells, smooth muscle, fibroblasts, or endothelial cells. A white cell pellet prepared from the buffy coat of venous blood fixed in glutaraldehyde failed to show any abnormal inclusions.

CASE 6 GM $_{1}$ gangliosidosis, TYPE 1

A 6 month old girl with psychomotor retardation, visceromegaly, and cherry-red spots at the maculae, was found to have a markedly reduced blood level of beta galactosidase. The most striking feature in a skin biopsy specimen was tremendous vacuolation of endothelial and perithelial cells (Fig. 8), fibroblasts, and smooth muscle. These vacuoles were empty or contained only small 


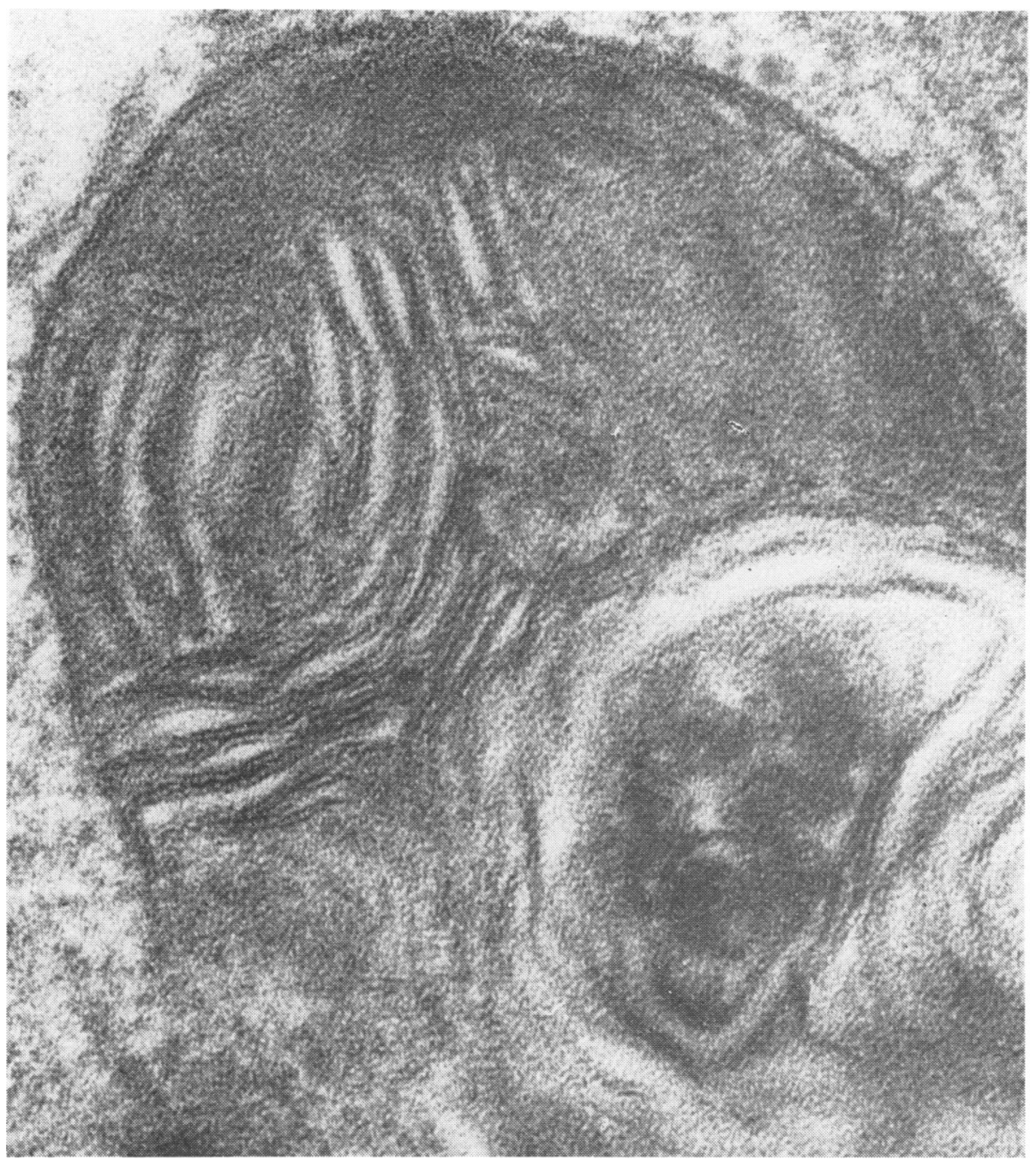

Fig. 3 Case 2. Late onset Tay-Sachs disease. Lipid body with triple membranes in unmyelinated cutaneous axon. $\times 80000$. 


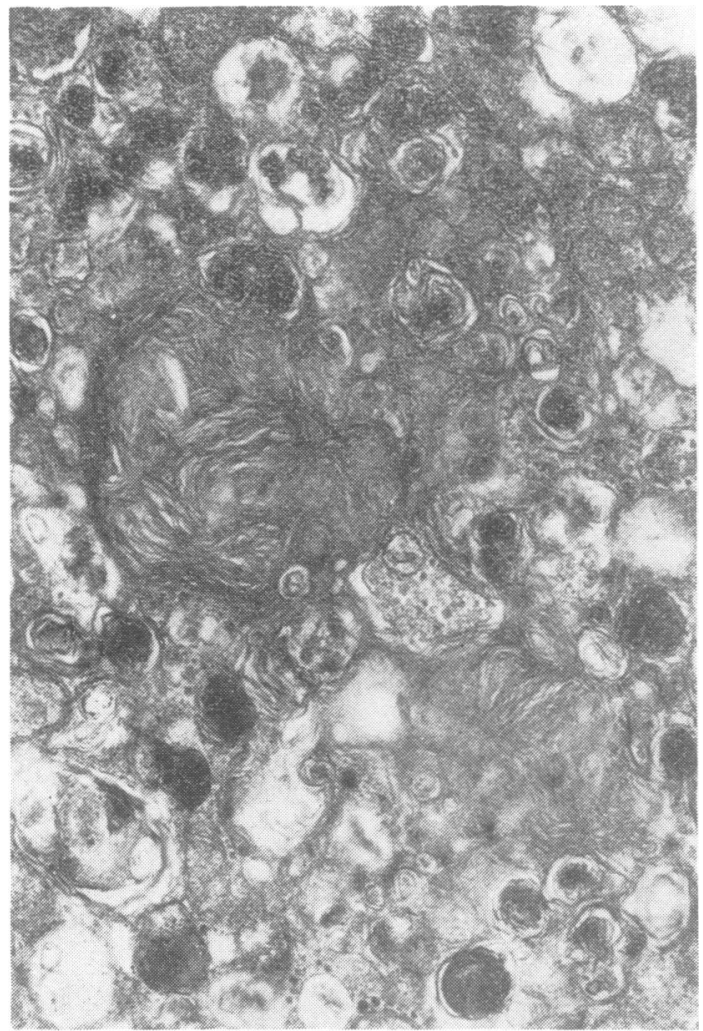

Fig. 4 Case 2. Late onset Tay-Sachs disease. Complex lipid and small dense bodies in cutaneous axon. $\times 31100$.

shreds of membrane. Marked vacuolation was also present in lymphocytes from the peripheral blood (Fig. 9). Only unmyelinated nerves were seen in the skin. Many of these were distended by osmiophilic dense bodies identical with those seen in the other children. Skin and blood samples of both parents were normal.

\section{Discussion}

All six children had abnormal skin. Vacuolation of cells is a well known feature in various tissues in $\mathbf{G M}_{1}$ gangliosidosis and renders the diagnosis easy, even with the light microscope. These vacuoles may represent the dissolved residuum of water soluble glucosaminogalactan (Lowden et al., 1973).

The inclusions in the axons could only be seen with the electron microscope, and were not visible in $1.0 \mu \mathrm{m}$ section stained with toluidine blue. There were two types. In infantile and late onset Tay-Sachs disease, the zebra bodies and complex

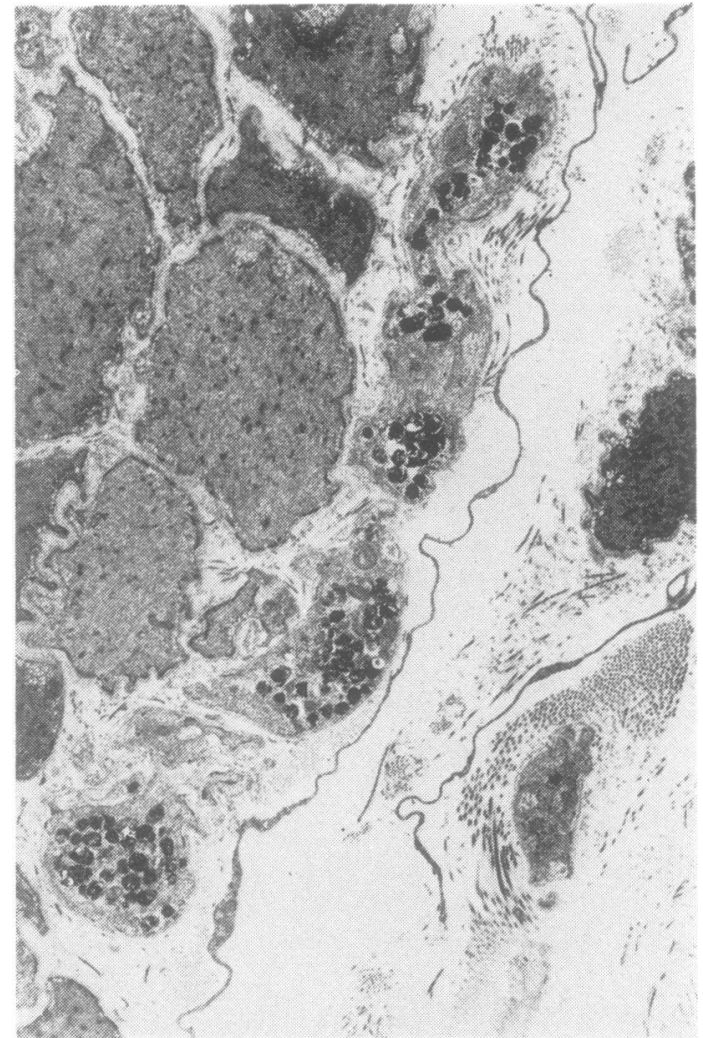

Fig. 5 Case 4. Juvenile Sandhoff disease. A cutaneous axon travelling along smooth muscle is distended by numerous dense bodies. $\times 5600$.

laminar lipid deposits encountered may be the ganglioside. Intermingled with these, much more prominent, and as the only inclusion in the cases of generalised gangliosidosis type 1 and juvenile Sandhoff disease, were osmiophilic dense bodies, usually without internal structure, but occasionally showing partial concentric lamination. Buxton et al. (1972) described in late onset $\mathbf{G M}_{2}$ gangliosidosis type 1, dense osmiophilic bodies in axons of the central nervous system and also dense osmiophilic granular debris. These authors considered these deposits to be part of the disease process. Adachi et al. (1974) in a study of eight fetuses afflicted with Tay-Sachs disease found in the ganglion cells of the retina electron-dense granular material which showed a transition to membranebound cytosomes and eventually to zebra bodies. Suzuki et al. (1970) found in the neurones of necropsy specimens of a girl suffering from juvenile $\mathrm{GM}_{z}$ gangliosidosis, a mixture of membranous cytoplasmic bodies, zebra bodies, irregular 


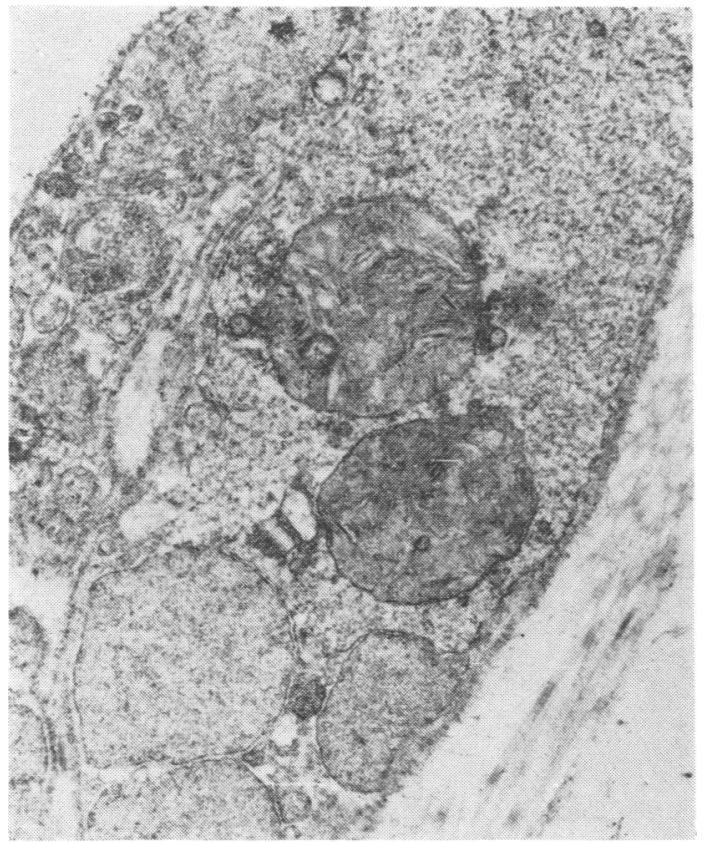

Fig. 6 Case 4. Juvenile Sandhoff disease. Membranebound zebra bodies in Schwann cell cytoplasm. $\times 24000$.

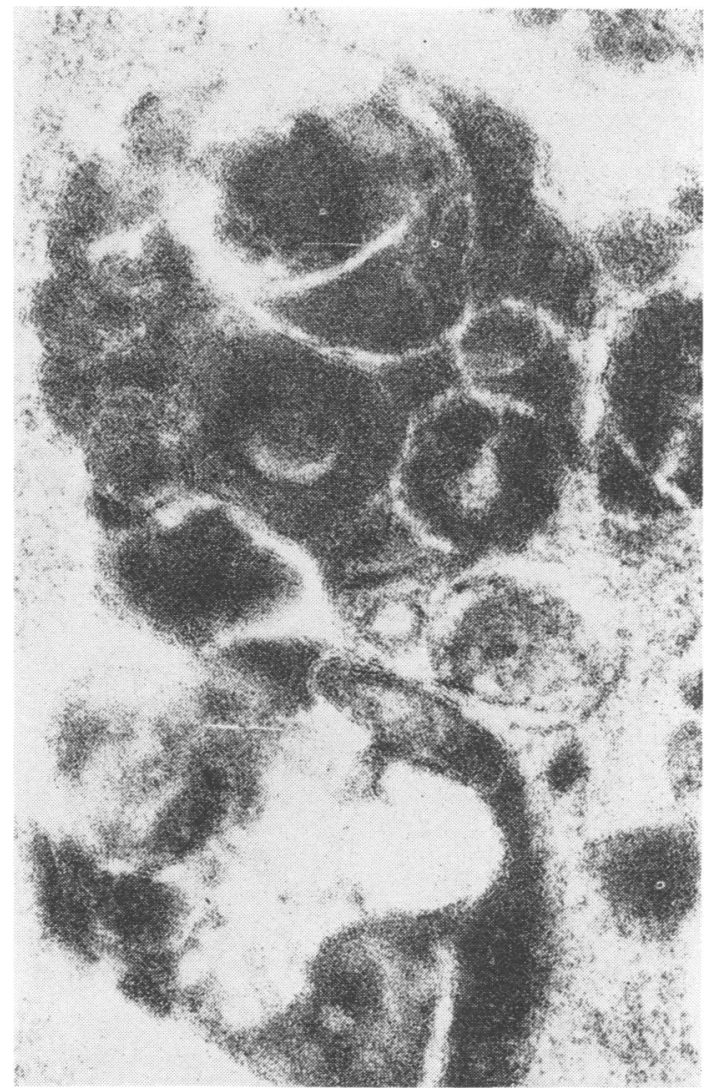

Fig. 7 Case 5. Juvenile Sandhoff disease. Large amorphous dense bodies in cutaneous axon. $\times 92000$.

be an expression of the 'dying back' process.

Only a few specific lipid inclusions were seen in Schwann cells in one of the two patients with juvenile Sandhoff disease. This contrasts with the very generalised storage prevalent in the infantile type (Dolman et al., 1973) and thus conforms to the general pattern of inborn errors of metabolism, in which the disease, and with it any storage, tends to be milder, the later the age of onset. In keeping with this concept are also the negative findings in parents of the patients.

Supported in part by a grant of the BC Medical Services Foundation-Vancouver Foundation. The biochemical work was performed by Dr D. Applegarth and Dr S. Wood. be laden with such debris, swept there peripheral axoplasmic flow. These deposits may 


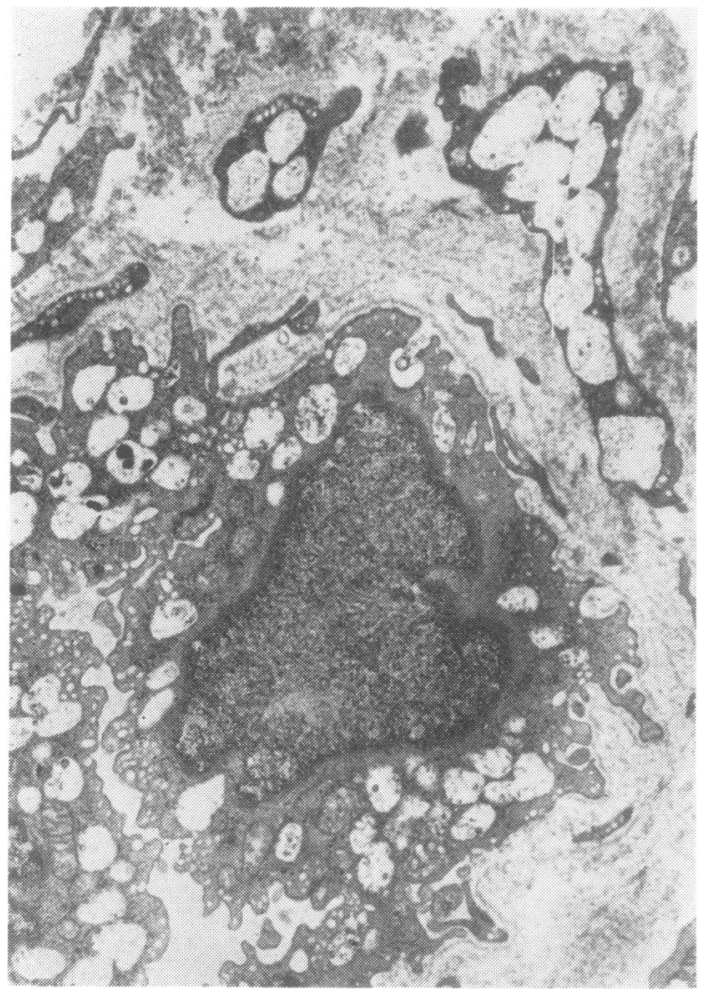

Fig. 8 Case 6. Generalised GM1 gangliosidosis. Vacuolated endothelial and perithelial cells in skin biopsy. $\times 11300$.

\section{References}

Adachi, M., Schneck, L., and Volk, B. W. (1974). Ultrastructural studies of eight cases of fetal TaySachs disease. Laboratory Investigation, 30, 102112.

Andermann, F., Andermann, E., Carpenter, S., Karpati, G., and Wolfe, L. (1975). Late onset $\mathrm{GM}_{2}$ gangliosidosis in two Lebanese families. American Journal of Human Genetics, 26, 10A.

Buxton, P., Cummings, J. N., Ellis, R. B., Lake, B. D., Mois, W. G. P., Roberts, J. R., and Young, E. P. (1972). A case of $\mathbf{G M}_{2}$ gangliosidosis of late onset. Journal of Neurology, Neurosurgery, and Psychiatry, 35, 685-692.

Carpenter, S., Karpati, G., and Andermann, F. (1972). Specific involvement of muscle, nerve and skin in late infantile and juvenile amaurotic idiocy. Neurology (Minneapolis), 22, 170-186.

Dolman, C. L., Duke, R. J., and Chang, E. (1973).

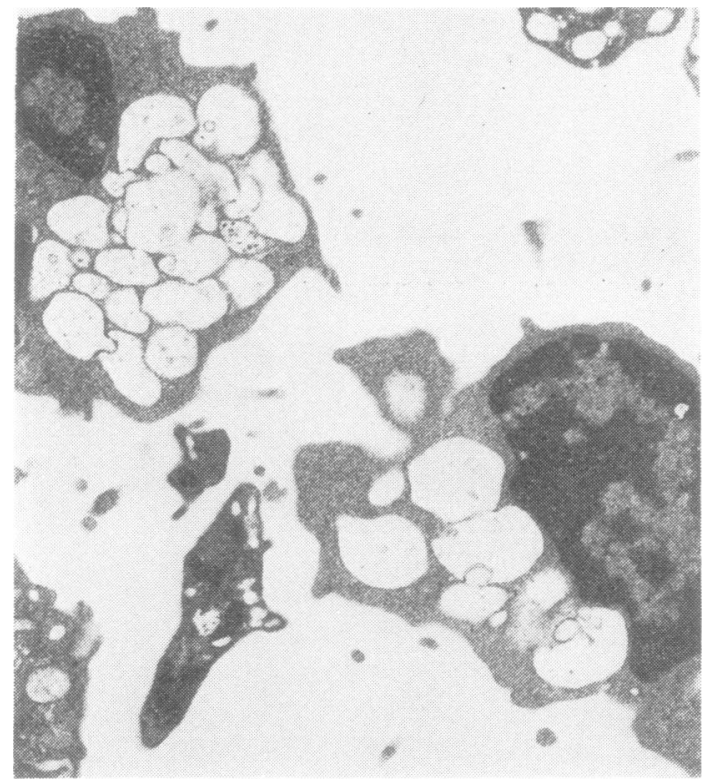

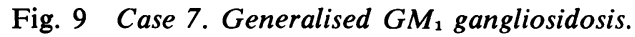
Vacuolated lymphocytes. $\times 11200$.

Pathologic findings in Sandhoff disease. Archives of Pathology, 96, 272-275.

Dolman, C. L., MacLeod, P. M., and Chang, E. (1975). Skin punch biopsies and lymphocytes in the diagnosis of lipidosis. Canadian Journal of Neurological Science, 2, 67-73.

Lowden, J. A., Cutz, E., Conen, P. E., Rudd, N., and Doran, T. A. (1973). Prenatal diagnosis of GM $_{1}$ gangliosidosis. New England Journal of Medicine, 288, 225-228.

O'Brien, J. S., Bernett, J., Veath, M. L., and Paa, D. (1975). Lysosomal storage disorders. Archives of Neurology (Chicago), 32, 592-599.

Patel, V., Goebel, H. H., Watanabe, I., and Zeman, W. (1974). Studies on $\mathrm{GM}_{1}$ gangliosidosis type II. Acta Neuropathologica, 30, 155-173.

Suzuki, K., Suzuki, K.. Rapin, I., Suzuki, Y., and Ishii, N. (1970). Juvenile $\mathbf{G M}_{2}$ gangliosidosis. Neurology (Minneapolis), 20, 190-204. 